2003s-48

\title{
Piece Rates, Fixed Wages and Incentives: Evidence from a Field Experiment
}

\author{
Bruce Shearer
}

\begin{tabular}{c}
\hline Série Scientifique \\
Scientific Series
\end{tabular}

Montréal

Août 2003

(C) 2003 Bruce Shearer. Tous droits réservés. All rights reserved. Reproduction partielle permise avec citation du document source, incluant la notice $\odot$.

Short sections may be quoted without explicit permission, if full credit, including $@$ notice, is given to the source.
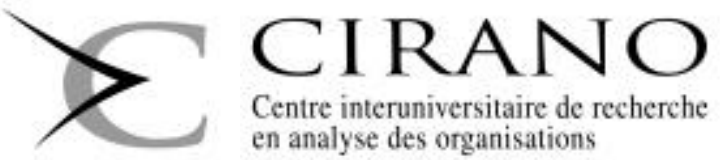

en analyse des organisations 


\section{CIRANO}

Le CIRANO est un organisme sans but lucratif constitué en vertu de la Loi des compagnies du Québec. Le financement de son infrastructure et de ses activités de recherche provient des cotisations de ses organisationsmembres, d'une subvention d'infrastructure du ministère de la Recherche, de la Science et de la Technologie, de même que des subventions et mandats obtenus par ses équipes de recherche.

CIRANO is a private non-profit organization incorporated under the Québec Companies Act. Its infrastructure and research activities are funded through fees paid by member organizations, an infrastructure grant from the Ministère de la Recherche, de la Science et de la Technologie, and grants and research mandates obtained by its research teams.

Les organisations-partenaires / The Partner Organizations

PARTENAire Majeur

. Ministère du développement économique et régional [MDER]

PARTENAIRES

. Alcan inc.

. Axa Canada

. Banque du Canada

. Banque Laurentienne du Canada

. Banque Nationale du Canada

. Banque Royale du Canada

. Bell Canada

. Bombardier

. Bourse de Montréal

. Développement des ressources humaines Canada [DRHC]

. Fédération des caisses Desjardins du Québec

- Gaz Métropolitain

. Hydro-Québec

. Industrie Canada

. Ministère des Finances [MF]

. Pratt \& Whitney Canada Inc.

. Raymond Chabot Grant Thornton

. Ville de Montréal

. École Polytechnique de Montréal

. HEC Montréal

. Université Concordia

. Université de Montréal

. Université du Québec à Montréal

. Université Laval

. Université McGill

AsSOCIÉ À :

. Institut de Finance Mathématique de Montréal (IFM ${ }^{2}$ )

. Laboratoires universitaires Bell Canada

. Réseau de calcul et de modélisation mathématique $\left[\mathrm{RCM}^{2}\right]$

. Réseau de centres d'excellence MITACS (Les mathématiques des technologies de l'information et des systèmes complexes)

Les cahiers de la série scientifique (CS) visent à rendre accessibles des résultats de recherche effectuée au CIRANO afin de susciter échanges et commentaires. Ces cahiers sont écrits dans le style des publications scientifiques. Les idées et les opinions émises sont sous l'unique responsabilité des auteurs et ne représentent pas nécessairement les positions du CIRANO ou de ses partenaires.

This paper presents research carried out at CIRANO and aims at encouraging discussion and comment. The observations and viewpoints expressed are the sole responsibility of the authors. They do not necessarily represent positions of CIRANO or its partners.

ISSN 1198-8177 


\title{
Piece Rates, Fixed Wages and Incentives: Evidence from a Field Experiment ${ }^{*}$
}

\author{
Bruce Shearer ${ }^{\dagger}$
}

\section{Résumé / Abstract}

Des données expérimentales sont utilisées afin de mesurer le gain en productivité réalisé quand des travailleurs sont payés à la pièce plutôt qu'à taux fixe. L'expérience a été complétée dans une entreprise qui s'occupe de plantation d'arbres et fournit des observations quotidiennes sur la productivité individuelle de chaque travailleur sous les deux systèmes de compensation. Des méthodes statistiques sans restriction mesurent le gain en productivité à 20\%. Étant donnée que les conditions de plantation affectent potentiellement la productivité, les méthodes structurelles sont utilisées afin de généraliser les résultats en dehors de l'expérience. Les résultats structurels suggèrent que le gain en productivité, en dehors des conditions expérimentales, sera au moins de $21.7 \%$.

Mots clés : Économétrie des contrats, incitations, expériences.

Data from a field experiment are used to estimate the gain in productivity that is realized when workers are paid piece rates rather than fixed wages. The experiment was conducted within a tree-planting firm and provides daily observations on individual worker productivity under both copensation systems. Unrestricted statistical methods estimate the productivity gain to be $20 \%$. Since planting conditions potentially affect incentives, structural econometric methods are used to generalize the experimental results to out-of-samples conditions. The structural results suggest that the average productivity gain, outside of the experimental conditions, would be at least $21.7 \%$.

Keywords: Econometrics of Contracts, Incentives, Experiments.

Codes JEL : J3, L2, C9

\footnotetext{
* I acknowledge research support from CIRANO, FCAR and SSHRC. For helpful comments and suggestions I thank Lorne Carmichael, Chris Ferrall, Chris Flinn, Lynda Khalaf, David Margolis, Paul Oyer, Harry Paarsch, John Rust and Marc Van Audenrode. I also thank participants at the Canadian Economics Association, the Econometrica Society's $8^{\text {th }}$ World Congress, the Numerical Intensive Economic Policy Analysis (Queen's University), the Econometrics of Strategy and Decision Making (Yale University), the Stanford Institute of Theoretical Economics, and seminar participants at CREST (Paris), GATE (Lyons), McGill, New York and Toulouse. A major part of this paper was completed while I was visiting CREST - I thank its members for their generous hospitality.

† Département d'économique, Université Laval, CIRPÉE and CIRANO, Québec, Québec, G1K 7P4, Canada, email: Bruce.Shearer@Ecn.ULlaval.ca, tel. (418) 656-2131(\#5606), fax (418) 656-7798.
} 


\section{Introduction}

Measuring how workers react to incentives has important implications for determining the relevance of economic theories (e.g. Hart and Holmstrom, 1987) as well as the personnel policies that are based on those theories (Milgrom and Roberts, 1992; Lazear, 1998). Recent empirical work in this area has concentrated on using firm-level data to measure the productivity effects of different compensation systems; i.e. incentive effects. Examples include Ichniowski, Shaw and Prennushi (1997), Lazear (2000) and Paarsch and Shearer $(1999,2000) .{ }^{1}$ Of particular concern in the measurement of incentive effects is the possible endogeneity of the compensation system. Since observed compensation systems represent choices made by the firm, if factors which are unobservable to the econometrician affect both the firm's choice and worker productivity, then simple comparisons of worker performance under different compensation systems will fail to identify the incentive effect (Ehrenberg, 1990; Prendergast, 1999).

Perhaps the most direct way to solve this endogeneity problem is to gather experimental evidence. An experimental setting permits the compensation system to be varied exogenously allowing direct measurement of the incentive effect within the experiment. This eliminates the need for strong functional form assumptions (Paarsch and Shearer, 1999, 2000) or assuming certain variables as instruments to identify the incentive effect in the data.

In this paper, I use data from a field experiment to measure the gain in productivity that is realized when workers are paid piece rates rather than fixed wages. The experiment took place within a tree-planting firm operating in the province of British Columbia, Canada. The firm in which the experiment was conducted usually pays its workers in proportion to the number of trees planted per day (i.e. a piece rate). To complete the experiment, nine male planters were randomly selected from this firm. These planters were then randomly allocated to plant under fixed wages and piece rates. Each worker involved in the experiment was observed planting under

\footnotetext{
1 See Chiappori and Salanié (2000) for a survey of empirical work on contracts.
} 
both piece rates and fixed wages. In total the experiment provided 120 observations on daily productivity (60 under each compensation system). I use these experimental data to measure the percentage difference in average productivity when workers are paid piece rates rather than fixed wages. I begin with an unrestricted comparison of mean productivity. This comparison reveals a $20 \%$ increase in worker productivity when workers are paid piece rates rather than fixed wages.

Identifying the incentive effect within an experiment is potentially restrictive results only generalize to the extent that experimental conditions are representative of non experimental conditions. This comes to light within the present context since planting conditions (particularly the difficulty of the terrain) affect worker productivity (Paarsch and Shearer, 1999) and therefore potentially affect the incentive effect.

I use structural econometric methods, combined with the experimental data, to identify out-of-sample incentive effects. Structural methods identify behavioural parameters that determine the workers' reaction to changing conditions and compensation systems. Previous applications of structural econometric methods within the compensation literature have considered measuring the cost of moral hazard within the firm (Ferrall and Shearer, 1999, Margiotta and Miller, 2000 and Copeland and Monet, 2002), measuring productivity profiles (Shearer, 1996), as well as measuring incentive effects (Paarsch and Shearer, 1999, 2000 and Haley, forthcoming). The application of structural methods to experimental data is discussed in Keane and Wolpin, 1997 and Ferrall, 2002.

The structural model considers worker and firm behaviour under piece rates and fixed wages. I discuss identification of the incentive effect on three levels. First, applying the structural model to the experimental data identifies the incentive effect within the experiment. Second, it also identifies a lower bound to the incentive effect for non experimental data. The lower bound is achieved by evaluating the incentive effect when the variance of planting conditions goes to zero. Finally, the incentive effect for a particular set of non experimental planting conditions is identified up to 
the variance of those conditions. Non experimental data can be used to identify the incentive effect on non experimental conditions even though the non experimental data contains observations under one compensation system only - there is no need to perform additional experiments.

An important extension to the structural model is achieved by relaxing the assumption of perfect information to the firm over the distribution of planting conditions. Doing so allows the firm to make mistakes when judging planting conditions. These perception errors lead to a random-effects empirical specification that significantly improves the fit of the structural model. The parameters of the model are estimated on the experimental data using maximum-likelihood techniques. The random-effects formulation permits the calculation of both unconditional (averaged over all possible perception errors) and conditional incentive effects which condition on the specific errors of the firm. The structural model calculates an unconditional experimental incentive effect of $22.26 \%$ and a unconditional lower bound of $21.67 \%$. In general, the results suggest that the unconditional incentive effect is much less sensitive to planting conditions than the conditional incentive effect. It is noteworthy that these results are similar to those obtained in Paarsch and Shearer (2000) who used non experimental, firm-level data originating from the same industry. Paarsch and Shearer calculate an incentive effect of $21 \%$ using structural econometric methods to control for a tree-planting firm's endogenous choice between piece rates and fixed wages.

Estimation of the structural model also permits the evaluation of alternative compensation policies within the firm. Efficiency wages are considered as a possible alternative to piece rates - reflecting the effects of a permanent change to a fixed wage personnel policy. The efficiency wage that would induce effort levels equal to those observed under fixed wages in the experiment is calculated and its implied unit costs are compared to those achieved under piece rates. The results suggest that fixed wages would lead to a $2.7 \%$ increase in unit costs relative to piece rates in the present labour-market conditions. 
There are eight additional sections to the paper. The next section discusses the institutional details of the tree-planting industry and the firm in which the experiment took place. Section 3 outlines the design of the experiment. Section 4 presents an unrestricted analysis of the experimental data. Section 5 develops the structural model. Sections 6 discusses the identification results. Sections 7 and 8 present the structural results and policy analysis, and Section 9 concludes.

\section{Institutional Details}

The tree-planting industry of British Columbia is responsible for the reforestation of recently logged tracts of land. Contracts to re-forest a tract of land are typically awarded to tree-planting firms through a competitive auction whereby firms will bid on the price-per-tree that they are to receive for planting. These auctions typically take place in the autumn and are conducted by either the Ministry of Forests or the major logging firms. Planting ensues the following spring.

The tree-planting industry is well suited to the study of incentive effects. Good measures of worker productivity exist and there is no team production. Tree-planting firms are typically quite small, employing less than 100 planters. These planters work under the supervision of firm managers and monitors (usually in the ratio of 10 workers to one monitor). Planters are equipped with a shovel and a sack of seedlings which fit around the planter's hip. Each day they are assigned to plant trees in an area of land. To plant a tree, the planter digs a hole in the ground, places the seedling in the ground and fills the hole in.

Planting is simple yet physically exhausting work. The productivity of the planters is determined by their effort level as well as the conditions of the terrain on which they are planting. For example, if the ground is hard and rocky or covered in underbrush, it takes more time and effort to plant a given number of trees, reducing daily worker productivity. In general, planting conditions vary a great deal. Some sites have been prepared for planting, meaning that the underbrush and slash timber has been removed (often by burning the site). Other sites are unprepared and are 
therefore more difficult to plant.

The firm in which the experiment took place employs approximately 90 planters per year. These planters are divided into work groups under the supervision of one of the firm's managers (who is an owner of the firm). These work groups are assigned to plant contracts throughout British Columbia during the planting season from February to July. The work group on which the experiment was performed included approximately 30 workers.

The firm typically pays its workers piece rates. Under these contracts workers are paid strictly in proportion to their individual output - no base wage is received. Planting sites are divided into blocks which are areas of homogeneous terrain. The manager in charge of the contract sets the piece rate for each block on the basis of planting conditions on that block. Typically, higher piece rates correspond to tougher planting conditions. This is because the piece rate must satisfy the worker's laboursupply constraint. Since workers are paid in proportion to their productivity and since effort is costly, workers prefer to plant in easier ground where they can plant more trees for a given effort level. To induce planters to plant on more difficult terrain the piece rate must be increased (see Paarsch and Shearer, 1999, for further details). On rare occasions ${ }^{2}$ workers will be paid fixed wages. This occurs, for example, when planting conditions change a great deal between the time at which the contract is bid and the time at which it is planted. For example, the ministry of forests will sometimes unexpectedly prepare sites that have already been awarded. The firm may not have knowledge of the changed conditions until they arrive at the site to begin planting. When this occurs, rather than renegotiate the price per tree at which the contract is to be planted (which may be impossible due to time constraints), the firm will simply plant the contract under a fixed price and pay their planters fixed wages. In these cases fixed wages are determined by the planter's average wage under previous piece rate contracts.

2 Conversations with the firm manager revealed that fewer than one percent of planting days are paid under fixed wages. 


\section{Experimental Design}

The goal of the experiment was to measure the change in worker effort as the compensation system changed from piece rates to fixed wages. Since worker productivity depends on worker effort as well as planting conditions, measuring the incentive effect required changing the compensation system while holding planting conditions constant. Randomization over blocks on which to conduct the experiment proved to be impossible since the firm did not know in advance which blocks would be planted in a given year. Contracts that were planted for the ministry of forests could involve multiple years of planting. Often, the blocks that were planted in any given year were not decided upon until just before the planting was done.

Two concerns dominated the design of the experiment and the selection of blocks. The first was to keep the work environment as normal as possible. In this regard, workers were kept ignorant of the experiment taking place. This required explaining the change in the compensation system in a manner that would seem realistic to the workers. Thus, workers were told that the firm had not agreed on a tree price with the contractor for certain blocks of land to be planted. None of the workers involved in the experiment questioned this explanation provided for planting under fixed wages. The second concern was that the incentive effect be measured precisely. With this in mind, the blocks that were selected were large enough to allow the repeated observation of each worker planting under each compensation system.

The experiment was conducted under a randomized-block design. Three blocks of land were chosen on which to conduct the experiment. Each block of land was internally homogeneous in terms of planting conditions ${ }^{3}$, yet differed from the other two. Each block of land was divided into two parts, or compensation regions - one to be planted under piece rates and the other to be planted under fixed wages.

A group of 9 male planters was randomly selected from the firm to take part in the experiment. The sample was restricted to male planters in order to reduce the

\footnotetext{
3 Homogeneous in that the piece rate paid to workers was constant within the block.
} 
variation in observed productivity. At the beginning of planting on a given block, planters were randomly assigned to piece rates or fixed wages. At the beginning of each workday, each planter was then randomly assigned to an area of land within his compensation region, and informed of his compensation system for that particular day.

Each worker planted an equal number of days under each compensation system. Due to attrition (one planter unexpectedly returned to school) and differing sizes of the block of land, different numbers of workers planted on the different blocks; subsequently not every worker is observed on each block of land. However, any worker who is observed on a given block of land is observed under both piece rates and fixed wages on that block. Furthermore, each worker who plants on a given plot of land is observed for the same number of days (at least two) under piece rates and fixed wages.

The length of the work day was held constant under both compensation systems and the blocks were large enough so that censoring (due to finishing a block before the workday was completed) was not a problem. The same individual was responsible for monitoring the workers under both compensation systems. Finally, the planting was controlled for quality by the firm and there were no differences under the two compensation systems during the experiment.

\section{Experimental Data}

The experimental data are presented in Table 1. The sample consists of 120 planting days, of which 60 took place under piece rates and 60 under fixed wages. The average daily productivity of these workers was 1146.67 trees and the standard deviation was 278.54. Workers were more productive under piece rates than fixed wages - the difference in average productivity being 219 trees. This represents an increase in average productivity of approximately 21 percent when workers were paid piece rates. The variance of worker output is higher under piece rates than fixed wages, reflecting the fact that workers adjust their effort to changing conditions when 
they are paid piece rates. Workers also earned more when planting under piece rates. To see if the increase in earnings outweighed the increase in productivity, the final column of Table 1 presents data on unit costs - daily earnings divided by daily productivity. These show that piece rates provided lower unit costs than fixed wages, the decrease being in the order of 13 percent. ${ }^{4}$

Table 2 considers average productivity across the blocks used in the experiment. These blocks (denoted 1,2 and 3) had piece rates of $\$ 0.17, \$ 0.18$, and $\$ 0.20$. The average productivity under piece rates and fixed wages for each plot is given in columns 6 and 7 . Notice that average productivity is higher under piece rates on each plot, although the percentage difference varies. These facts suggest that blockspecific effects are an important determinant of worker productivity and incentives, reflecting differences in planting conditions.

Average productivity per plot is given in column 4. Notice the actual average productivity is not negatively related to the piece rate as would be expected from the manner in which the firm sets piece rates. Recall, the firm sets the piece rate in inverse relation to the difficulty of the planting conditions that the manager observes. However, average productivity is higher when the piece rate is $\$ 0.18$ than when it is $\$ 0.17$. This is due to the fact that the firm sometimes errs in their judgment of planting conditions during the bidding process resulting in a piece rate that is slightly too high or too low for a given plot of land. Below, the model will be extended to account for these perception errors.

Table 3 presents average productivity by individual planter and pay system. Column 3 shows the average productivity per planter ranges from 992.5 trees to 1330 trees per day, suggesting that individual heterogeneity is present in the sample. Columns 4 and 5 give the average productivity for each planter under piece rates and

4 Some caution must be exercised in interpreting this statistic. In particular, given effort is lower under fixed wages, workers should be willing to accept lower wages than under piece rates. This suggests that the observed unit costs under fixed wages are higher than need be. I return to this point in Section 8 below. 
fixed wages. Again average productivity for each planter is higher under piece rates. ${ }^{5}$

\subsection{The Incentive Effect}

I calculate two measures of the incentive effect. The first is given by

$$
H_{j}^{1}=\sum_{i=1}^{I_{j}} \frac{n_{i j}}{N_{j}} \frac{\{\mathcal{E}[Y \mid p r, I=i, J=j]-\mathcal{E}[Y \mid f w, I=i, J=j]\}}{\mathcal{E}[Y \mid f w, I=i, J=j]}
$$

This is simply the weighted average of the percentage increase in productivity experienced by individual $i$ on block $j$, where $I_{j}$ denotes the number of individuals planting on block $j, n_{i j}$ denotes the number of observations on individual $i$ on block $j$ and $N_{j}$ denotes the total number of observations on block $j$. Since this measure depends on blocks and individuals it may be biased in small samples. In particular, there may not be enough observations per individual to consistently estimate (4.1). An alternative estimator is achieved by integrating out the individual effects

$$
H_{j}^{2}=\frac{\mathcal{E}[Y \mid p r, J=j]-\mathcal{E}[Y \mid f w, J=j]}{\mathcal{E}[Y \mid f w, J=j]} .
$$

The overall incentive effect within the experiment can then be calculated by

$$
H^{l}=\sum \frac{N_{j}}{N} H_{j}^{l} \quad l \in\{1,2\}
$$

To further investigate the statistical significance of the incentive effect I calculate the sample equivalents of $H_{1}$ and $H_{2}$ to be $19.86 \%$ and $19.78 \%$ respectively. The bootstrapped standard errors are 0.0185 and 0.0187 suggesting that the estimates are statistically significant. I also calculate these measures by plot. These are given in Table 4. The standard errors are calculated from 10,000 bootstrapped samples. 6

5 Averaging hides some variability in the data. In particular, analyzing individual productivity by plot and compensation system reveals that in three cases a planter planted fewer trees under piece rates than fixed wages on the same plot.

6 The bootstrap procedure replicates the composition of the observed sample with respect to individuals, $i$, plots, $j$, and the compensation system, $k$. I take the observed sample $S$ to be made up of a number of subsamples $S_{i j k}=\left\{Y_{i_{i j k}}, Y_{2_{i j k}}, \ldots, Y_{N_{i j k}}\right\}$ of size $N_{i j k}$. For each subsample I sample, with replacement, $N_{i j k}$ observations. 
In order to assess the reliability of these estimators in small samples I calculate the estimated bias as well as the bias relative to the standard error (Efron and Tibshirani 1993, Mackinnon and Smith 1998). These values are small in both cases, although smaller for the estimator $H^{2}{ }^{7}$

\subsection{Generalizing the Incentive Effect}

The experimental data provides exogenous variation in the worker's compensation scheme which allows for the use of simple mean comparisons to calculate the incentive effect. Statistical estimators can summarize what happened in the experiment without imposing behavioural restrictions (Burtless, 1995). Since these statistical estimators compare averages within a given context, they do not generalize to conditions beyond those observed in the experiment unless the incentive effect is independent of conditions. This would happen only if conditions did not vary across plots or worker effort was independent of conditions. If the incentive effect does depend on conditions then unrestricted methods require that a new experiment be performed on each plot for which the incentive effect is to be calculated. This reflects Heckman and Smith's (1995) black-box critique of reduced form analysis of experimental data. Generalizing the incentive effect beyond the experimental conditions in these circumstances requires estimating a restricted or structural model. A structural model generates the observed statistics from economic behaviour. The mapping from behaviour to data identifies structural parameters which govern how worker effort changes as conditions change. Estimates of these parameters obtained from the experimental data can then be used to generalize the incentive effect outside of the experimental conditions.

\section{Theoretical Model}

This section develops a structural model of worker productivity under piece rates and fixed wages. The model derives worker effort functions as equilibrium responses to the personnel policy observed within the experimental firm.

7 Efron and Tibshirani suggest that the bias can be safely ignored when its value relative to the standard error is below 0.25 . 


\subsection{The Personnel Policy of the Firm}

The piece-rate contracts that are typically paid to workers are based on output measures. The number of trees planted in a given day is counted and workers are paid in proportion to this number. However, the firm did not set output standards under fixed wages. This was confirmed by the firm manager, but is also evident in the data. If workers were required to meet a daily production standard, they would choose an effort level that met that standard exactly. While it is possible that the standard be individual and plot specific, there would be a degenerate distribution of productivity (conditional on supplying effort) at the production standard for a given plot and individual. Yet, Table 5 shows that the distribution of observed productivity conditional on an individual and plot has positive variation - the standard deviation attains $14 \%$ of average productivity in some cases. I therefore model the firm as monitoring input under fixed wages.

\subsection{Enforceable Contracts}

While output measures can readily be verified, contracts based on input measures must be self enforcing implying that a surplus to the relationship must exist. (Bull, 1987, MacLeod and Malcolmson, 1989).

Assumption A1. The full surplus of the employer-employee relationship goes to the worker.

With zero surplus going to the firm, the firm would default on an implicit piece-rate contract (MacLeod and Malcolmson, 1989) - any piece-rate contract must be independent of effort. The threat of an employee quitting, in the face of the firm claiming that the worker had provided less than the observed effort, has no disciplinary effect since workers can be immediately replaced. Conversely, a fixed-wage (or termination) contract can support equilibrium effort since the firm has no incentive to cheat (the wage must be paid anyway) and workers do not want to lose their job. 


\subsection{Technology and Preferences}

Daily productivity is determined by

$$
Y=E S
$$

where $E$ represents the worker's effort level, and $S$ is a productivity shock representing planting conditions beyond the worker's control (such as the hardness of the ground). I assume that $S$ follows a lognormal distribution with parameters $\mu$ and $\sigma^{2}$; i.e., $\ln S \sim N\left(\mu, \sigma^{2}\right)$. Workers have the utility function defined over daily earnings, $w$, and effort, $E$,

$$
U_{i}(w, E)=w-C_{i}(E) .
$$

$C_{i}(E)$ represents worker $i$ 's monetary cost of effort and is parameterized as

$$
C_{i}(E)=\frac{\kappa_{i}}{\eta} E^{\eta}, \quad \eta>1, \kappa_{i}>0
$$

where $\kappa_{i}$ captures individual heterogeneity, and $\eta$ determines the curvature of the cost function. ${ }^{8}$ Alternative utility is given by $\bar{u}$.

8 Assuming risk neutrality allows me to concentrate on incentives, abstracting from risk. While introducing risk aversion is possible, empirical attempts to do so have brought about mixed results in terms of identification. Ferrall and Shearer (2000) were unable to separately identify the cost of effort parameter from the risk aversion parameter in the case where workers had exponential utility. 


\subsection{Timing}

The timing of the model is as follows. For each plot of land to be planted:

1. Nature chooses $\left(\mu, \sigma^{2}\right)$;

2. the firm observes $\left(\mu, \sigma^{2}\right)$ and then selects a contract

$$
\Omega= \begin{cases}r & \text { if piece-rate contract } \\ W & \text { if fixed-wage contract }\end{cases}
$$

3. the worker observes $\left(\mu, \sigma^{2}\right)$ and $\Omega$ and either accepts or rejects the contract;

4. conditional on accepting the contract the worker observes a particular value of $S$ and chooses an effort level, producing $Y$;

5. the firm observes $Y$ and $E$ and pays wages.

\subsection{Piece Rates}

Under piece rates, in accordance with the observed contract, $w=r Y$.

Let $e_{i}$ denote the optimal level of effort chosen by worker $i$. Conditional on $s$, a realization of $S$,

$$
e_{i}=\left[\frac{r s}{\kappa_{i}}\right]^{\gamma}
$$

where $\gamma=1 /(\eta-1)$.

In order for workers to accept the contract it must satisfy their expected utility constraint. Given the contract has only one instrument and workers are heterogeneous, some workers will earn rents. I assume that the piece rate is chosen to satisfy the alternative utility constraint of the lowest-ability worker in the firm; that is, the worker with ability level $\kappa_{h}$ where

$$
\kappa_{h}=\max \left\{\kappa_{1}, \kappa_{2}, \ldots, \kappa_{n}\right\}
$$

As such, $r$ solves agent $h$ 's expected utility constraint

$$
\frac{r^{\gamma+1}}{\kappa_{h}^{\gamma}(\gamma+1)} \mathcal{E}\left(S^{(\gamma+1)} \mid \mu, \sigma^{2}\right)=\bar{u}
$$


where $\mathcal{E}$ denotes the expectation operator. Workers with lower costs of effort earn rents equal to

$$
\left[\left(\frac{\kappa_{h}}{\kappa_{i}}\right)^{\gamma}-1\right] \bar{u} .
$$

Output for individual $i$ is given by

$$
Y_{i}^{p r}=\left(\frac{r}{\kappa_{i}}\right)^{\gamma} S^{\gamma+1}
$$

Taking logarithms of (5.4) and substituting into (5.6) gives daily productivity for individual $i$ on contract $j$ as

$$
\ln Y_{i j}^{p r}=\ln (\gamma+1)+\ln \bar{u}-\ln r_{j}+\gamma\left(\ln \kappa_{h}-\ln \kappa_{i}\right)-(\gamma+1)^{2} \frac{\sigma_{j}^{2}}{2}+\epsilon_{i j}^{p r}
$$

where $\epsilon_{i j}^{p r}=(\gamma+1)\left(\ln S_{i j}-\mu_{j}\right) \sim N\left(0,(\gamma+1)^{2} \sigma_{j}^{2}\right)$.

\subsection{Fixed Wages}

While theoretical models of effort determination under fixed wages are well known (Shapiro and Stiglitz (1984), MacLeod and Malcolmson (1989)) little empirical work exists that has taken these models seriously as data-generating processes (although one important exception is the work of Flinn, 1997). In their simplest form, these models generate incentives through termination contracts - the worker is fired if his performance falls below some standard set by the firm. Incentives are provided through the presence of a surplus to continuing the relationship with the firm. Effort is monitored with a certain probability and deviations from an agreed upon effort level result in the worker being fired. ${ }^{9}$ The threat of termination will provide incentives to the worker as long as the agreed upon effort level, denoted $e^{f w}$ satisfies a no-shirking condition; namely,

$$
\mathcal{E}\left[U\left(e^{f w}\right)\right] \geq \arg \max _{E} \mathcal{E}[U(\text { shirking })]
$$

9 Alternatively, one could allow the firm to observe a signal of effort and set the incentive standard on the basis of that signal. However, in such a model equilibrium effort levels would imply non-zero punishment probabilities which are inconsistent with the data. For example, if the signal was worker output and productivity shocks occurred between the worker's effort choice and the realization of output, then random differences between output and actual effort would imply a positive firing probability in equilibrium. 
Given the fixed wage payments to these workers occur over a relatively short period of time, I consider the fixed-wage planting to be of one period duration only and the environment to be stationary. ${ }^{10}$ In contrast with traditional shirking models (Shapiro and Stiglitz (1984) and MacLeod and Malcolmson (1989)) the future surplus to the worker is generated under piece-rate planting which resumes when the experiment is finished. Note that this surplus is not necessarily equal to the rent calculated in (5.5). In particular, $\bar{u}$ refers to the level of utility the worker earns at zero labour-market effort. Yet, the worker may find employment at another firm, tree planting or otherwise, after a certain period of time. The surplus then incorporates how long it will take the worker to find another job and the present discounted value of lost income during the search and at the alternative employment.

Let $\delta$ denote the probability that a worker is monitored. ${ }^{11}$ Workers who are monitored and who supply effort less than $e^{f w}$ are fired while those who supply effort greater than $e^{f w}$ return to plant under piece rates. The expected utility of shirking $\left(E<e^{f w}\right)$ is

$$
\mathcal{E}[U(\text { shirking } \mid F W)]=W-C(E)+\delta \beta \mathcal{E}[V \mid F]+[1-\delta] \beta \mathcal{E}[V \mid P R]
$$

where $\beta$ is the discount factor and $\mathcal{E}[V \mid F]$ and $\mathcal{E}[V \mid P R]$ represent the worker's expected present discounted utility from being fired and piece-rate work respectively. Note that a worker who chooses to shirk will set his effort level to zero since the detection probability is independent of effort.

The expected utility of not shirking $\left(E \geq e^{f w}\right)$ is

$$
\mathcal{E}[U(E \mid F W)]=W-C(E)+\beta \mathcal{E}[V \mid P R]
$$

10 This representation of the experiment abstracts from dynamic factors affecting the choice of effort within the experiment. It also assumes that the incentive contribution of expected future fixed-wage planting is negligible. Given, fixed-wage planting accounts for fewer than $1 \%$ of all planting days, this does not appear overly restrictive.

11 A probability less than one allows for differences in the firm's ability to monitor input and output. 
since the probability of being fired is zero and continuation in the firm implies working under piece rates. Since there is no gain to the worker of setting $E>e^{f w}$ a nonshirking worker will set $E=e^{f w}$, the level of effort demanded by the firm.

The incentive-compatibility constraint is given by

$$
C(E) \leq \delta \beta[\mathcal{E}[V \mid P R]-\mathcal{E}[V \mid F]]
$$

This defines the set of effort levels which the worker will supply for a given monitoring technology and labour-market conditions. The incentive-compatibility constraint is independent of the wage paid since the worker gets this wage for one period, regardless of his behaviour. ${ }^{12}$ I assume that the firm chooses to enforce the maximum effort level that the worker is willing to produce. Using $(5.1)^{13}$

$$
e_{i}^{f w}=\left(\frac{\gamma+1}{\kappa_{i} \gamma}\right)^{\gamma /(\gamma+1)}\left[\delta \beta\left(\mathcal{E}\left[V_{i} \mid P R\right]-\mathcal{E}\left[V_{i} \mid F\right]\right)\right]^{\gamma /(\gamma+1)}
$$

giving equilibrium output

$$
Y_{i}^{f w}=\left(\frac{\gamma+1}{\kappa_{i} \gamma}\right)^{\gamma /(\gamma+1)}\left[\delta \beta\left(\mathcal{E}\left[V_{i} \mid P R\right]-\mathcal{E}\left[V_{i} \mid F\right]\right)\right]^{\gamma /(\gamma+1)} S .
$$

Taking logarithms of (5.13), using (5.4) and defining

$$
\mathcal{R}_{i}=\ln \left[\delta \beta\left(\mathcal{E}\left[V_{i} \mid P R\right]-\mathcal{E}\left[V_{i} \mid F\right]\right)\right]
$$

gives

$$
\begin{aligned}
\ln Y_{i j}^{f w}= & \frac{\ln \bar{u}}{\gamma+1}+\ln (\gamma+1)-\frac{\gamma}{\gamma+1} \ln \gamma+\frac{\gamma}{\gamma+1} \mathcal{R}_{i}+\frac{\gamma}{\gamma+1}\left(\ln \kappa_{h}-\ln \kappa_{i}\right)- \\
& \ln r_{j}-(\gamma+1) \frac{\sigma_{j}^{2}}{2}+\epsilon_{i j}^{f w} .
\end{aligned}
$$

where $\epsilon_{i j}^{f w}=\ln S_{i j}-\mu_{j} \sim N\left(0, \sigma_{j}^{2}\right)$.

12 This feature distinguishes this class of models from gift-exchange models. See, for example, Fehr and Gachter (2000).

13 In general one could imagine the firm selecting wages and effort to maximize expected profits subject to (5.11) and a labour-supply constraint. The assumed solution is equivalent to the efficiency wage in which (5.11) binds and the labour-supply constraint does not. 


\section{Identification}

The theoretical model leads to two empirical equations defined by (5.7) and (5.14). To assist in the discussion of identification of the restricted model, let $i_{1}$ denote the first individual in the experimental sample and $j_{1}$ denote the first block, and rewrite the system of equations given by (5.7) and (5.14) as

$$
\begin{aligned}
\ln Y_{i j}^{p r}+\ln r_{j} & =a_{0}+\ln (\gamma+1)+\gamma\left(\ln \kappa_{i_{1}}-\ln \kappa_{i}\right)-(\gamma+1)^{2} \frac{\sigma_{j}^{2}}{2}+\epsilon_{i j}^{p r} \\
\ln Y_{i j}^{f w}+\ln r_{j}= & \frac{a_{0}}{\gamma+1}+\ln (\gamma+1)-\frac{\gamma}{\gamma+1} \ln (\gamma)+\frac{\gamma}{\gamma+1}\left(\ln \kappa_{i_{1}}-\ln \kappa_{i}\right)+ \\
& \frac{\gamma}{\gamma+1} \mathcal{R}_{i}-(\gamma+1) \frac{\sigma_{j}^{2}}{2}+\epsilon_{i j}^{f w}
\end{aligned}
$$

where $a_{0}=\ln \bar{u}+\gamma\left(\ln \kappa_{h}-\ln \kappa_{i_{1}}\right)$.

Theorem 1: The restricted model (6.1) identifies

(i) $\gamma$

(ii) $\sigma_{j}^{2}$

(iii) $\ln \kappa_{i_{1}}-\ln \kappa_{i}$

(iv) $\ln \bar{u}+\gamma\left(\ln \kappa_{h}-\ln \kappa_{i_{1}}\right)=a_{0}$

(v) $\mathcal{R}_{i}$

(vi) $\mu_{j_{1}}-\mu_{j}$

\subsection{Incentive Effect}

Lemma 1: Conditional on a piece rate, $r_{j}$, equilibrium expected productivity under piece rates is independent of planting conditions $\mu_{j}$ and $\sigma_{j}^{2}$ and is given by

$$
\begin{aligned}
\mathcal{E}\left[Y \mid p r, r_{j}, i, \mu_{j}, \sigma_{j}\right] & =\bar{u}(\gamma+1)\left(\frac{\kappa_{h}}{\kappa_{i}}\right)^{\gamma} \frac{1}{r_{j}} \\
& =\exp \left\{a_{0}+\gamma\left(\ln \kappa_{i_{1}}-\ln \kappa_{i}\right)\right\} \frac{(\gamma+1)}{r_{j}}
\end{aligned}
$$


Since the piece rate is chosen to satisfy the worker's expected utility constraint, it contains all the relevant information concerning conditions when the worker is paid piece rates. What is more, there is a monotonic (negative) relationship between expected productivity and piece rates.

Lemma 2: Conditional on a piece rate, $r_{j}$, equilibrium expected productivity under fixed wages depends on planting conditions and is given by

$$
\begin{aligned}
& \mathcal{E}\left[Y \mid f w, r_{j}, i, \mu_{j}, \sigma_{j}\right]=(\gamma+1) \bar{u}^{\frac{1}{(\gamma+1)}}\left[\gamma^{-1}\left(\frac{\kappa_{h}}{\kappa_{i}}\right)\right]^{\frac{\gamma}{(\gamma+1)}} \frac{1}{r_{j}} \exp \left\{\frac{\gamma}{(\gamma+1)} \mathcal{R}_{i}-\gamma \sigma_{j}^{2} / 2\right\} \\
& =\frac{(\gamma+1)}{r_{j}} \exp \left\{\frac{a_{0}}{(\gamma+1)}+\frac{\gamma}{\gamma+1}\left(\ln \kappa_{i_{1}}-\ln \kappa_{i}+\mathcal{R}_{i}-\ln \gamma-(\gamma+1) \frac{\sigma_{j}^{2}}{2}\right)\right\} .
\end{aligned}
$$

Recall that the piece rate provides information as to planting conditions through (5.4). Thus, even though worker productivity under fixed wages is independent of the piece rate, the piece rate the worker would have received had the payment system been piece rates is still informative as to the planting conditions ${ }^{14}$. However, unlike the case for piece-rate planting, the piece rate does not contain all of the relevant information concerning expected productivity when workers are paid fixed wages. While planting conditions are the same under piece rates and fixed wages (for a given piece rate), the effort decision is different. In particular, while worker effort responds to conditions under piece rates, fixed-wage effort depends only on outside opportunities and is therefore independent of conditions. This lack of symmetry between piece rates and fixed wages is reflected in the presence of the term $\exp \left(-\gamma \sigma_{j}^{2}\right)$ in $(6.3)$, which captures the differences in worker reactions to changes in conditions, $\sigma^{2}$, under piece rates and

14 Note, as well, $\bar{u}$ affects $\mathcal{E}\left[Y \mid f w, r_{j}, i, \sigma_{j}\right]$ only through the relationship between $r_{j}$ and $\mu_{j}$. That is, a higher value of $\bar{u}$ implies that a given value of $r_{j}$ is associated with a larger value of $\mu_{j}$ (better planting conditions), leading to higher expected productivity under fixed wages. 
fixed wages.

Theorem 2: The restricted equilibrium incentive effect is written

$$
\begin{aligned}
& {\left[\bar{u} \gamma\left(\frac{\kappa_{h}}{\kappa_{i}}\right)^{\gamma}\right]^{\frac{\gamma}{(\gamma+1)}} \exp \left\{\gamma \frac{\sigma_{j}^{2}}{2}-\frac{\gamma}{(\gamma+1)} \mathcal{R}_{i}\right\}-1=} \\
& \exp \left\{\left[a_{0}+\gamma\left(\ln \kappa_{i_{1}}-\ln \kappa_{i}\right)-\mathcal{R}_{i}+\ln \gamma+(\gamma+1) \frac{\sigma_{j}^{2}}{2}\right] \frac{\gamma}{\gamma+1}\right\}-1
\end{aligned}
$$

The restricted model allows for generalizing the incentive effect to conditions beyond the experimental sample without performing separate experiments. In order to estimate the incentive effect on plot $j$, all that is required is an estimate of the variance for that plot, $\sigma_{j}^{2}$, which can be recovered by observing workers under either piece rates or fixed wages. Thus non experimental data on piece rate planting can be used to calculate the incentive effect without observing planters under fixed wages.

At a more general level, the restricted model allows for the estimation of a lower bound to the incentive effect for any conditions under which the firm is planting.

Theorem 3: A lower bound to the incentive effect for a given individual is given by (6.4) evaluated at $\sigma^{2}=0$.

To understand the lower bound consider Figure 1. The diagonal line $P P^{\prime}$ shows combinations of $\mu$ and $\sigma^{2}$ that give rise to the same piece rate for a given level of utility. From (5.4) the slope of $P P^{\prime}$ is $-(\gamma+1) / 2$. Furthermore, from Lemma 1, these same combinations of $\mu$ and $\sigma^{2}$ give rise to constant expected productivity under piece rates. Intuitively, this follows from the fact that the piece rate contains all relevant information about productivity under piece-rate planting. From Lemma 2 , the trade off between $\mu$ and $\sigma^{2}$ that keeps expected productivity under fixed wages constant is $-1 / 2$, the slope of $F F^{\prime}$. The line $P P^{\prime}$ is steeper than $F F^{\prime}$ since movements along $F F^{\prime}$ reflect changes in conditions only (since fixed-wage effort is independent of conditions), while movements along $P P^{\prime}$ indicate changes in conditions and effort - movements along $P P^{\prime}$ towards $P$ therefore increase the incentive effect. The lower bound occurs at the corner solution $\sigma^{2}=0$. At this point workers do not adjust their effort levels under piece rates since conditions are constant. The lower bound 
is significant in that it provides information about the incentive effect for any plot of land, whether or not production data is available.

\section{Structural Results}

Estimates from the structural model on the experimental data are given in Table 6. The value of the likelihood function is 87.451 . The incentive effect calculated from these estimates is equal to $25.7 \%$ when averaged across blocks. This is somewhat higher than the unrestricted estimate of $19.8 \%$ suggesting that the restricted model is having some difficulties in fitting the data. The predicted incentive effect on each block is $26 \%, 21 \%$ and $27 \%$ which are considerably different from the unrestricted estimates of $31 \%, 20 \%$ and $8 \%$.

Figure 2 graphs the predicted and observed average productivity under piece rates and fixed wages per block. It is clear from the graph that the model has difficulty matching piece rate productivity when the piece rate is $\$ .18$ and $\$ .20$. This derives from the fact that the model imposes an inverse relationship between piece rates and expected productivity, yet, as noted in Section 4, observed piece-rate productivity is higher when workers earn $\$ .18$ per tree than when workers earn $\$ .17$ per tree. In what follows I introduce errors in judgement over planting conditions to account for this anomaly.

\subsection{Perception Errors}

In order to account for perception errors I allow for the possibility that, instead of observing true conditions of $\mu_{j}$ on plot $j$, the firm observes an unbiased estimate of those conditions, denoted $\tilde{\mu}_{j}$. That is

$$
\mu_{j}=\tilde{\mu}_{j}+\nu_{j}
$$

where $\nu_{j} \sim N\left(0, \sigma_{\nu}^{2}\right)$ and $\mathcal{E}\left[\tilde{\mu}_{j} \nu_{j}\right]=0$.

Given that decisions over the piece rate and labour supply depend on $\tilde{\mu}$, equation (5.7) is now written 


$$
\ln Y_{i j}^{p r}=\ln (\gamma+1)+\ln \bar{u}-\ln r_{j}+\gamma\left(\ln \kappa_{h}-\ln \kappa_{i}\right)-(\gamma+1)^{2} \frac{\left(\sigma_{j}^{2}+\sigma_{\nu}^{2}\right)}{2}+\epsilon_{i j}^{p}
$$

where

$$
\epsilon_{i j}^{p}=(\gamma+1)\left(\ln S_{i j}-\mu_{j}+\nu_{j}\right)=\epsilon_{i j}^{p r}+(\gamma+1) \nu_{j}
$$

and $\epsilon_{i j}^{p r}$ is as in (5.7).

Similarly, equation (5.14) is now written

$$
\begin{aligned}
\ln Y_{i j}^{f w}= & \frac{\ln \bar{u}}{\gamma+1}+\ln (\gamma+1)-\frac{\gamma}{\gamma+1} \ln \gamma+\frac{\gamma}{\gamma+1} \mathcal{R}_{i}+\frac{\gamma}{\gamma+1}\left(\ln \kappa_{h}-\ln \kappa_{i}\right)- \\
& \ln r_{j}-(\gamma+1) \frac{\left(\sigma_{j}^{2}+\sigma_{\nu}^{2}\right)}{2}+\epsilon_{i j}^{f}
\end{aligned}
$$

where

$$
\epsilon_{i j}^{f}=\left(\ln S_{i j}-\mu_{j}+\nu_{j}\right)=\epsilon_{i j}^{f w}+\nu_{j}
$$

and $\epsilon_{i j}^{f w}$ is as in (5.14).

The model with perception errors reduces to a variant of the well known composite-error model. The first component, $\epsilon$, represents deviations of a given shock from its actual mean. The second component, $\nu$, represents deviations of the actual mean from the perceived mean.

I estimate the perception-error case as a random-effects model. The error structure is given by

$$
\begin{aligned}
\mathcal{E}\left[\epsilon_{i j}^{p}\right] & =0 \\
\mathcal{E}\left[\left(\epsilon_{i j}^{p}\right)^{2}\right] & =(\gamma+1)^{2}\left(\sigma_{j}^{2}+\sigma_{\nu}^{2}\right) \\
\mathcal{E}\left[\epsilon_{i j}^{p} \epsilon_{i j^{\prime}}^{p}\right] & =0 \\
\mathcal{E}\left[\epsilon_{i j}^{p} \epsilon_{i^{\prime} j}^{p}\right] & =(\gamma+1)^{2} \sigma_{\nu}^{2}
\end{aligned}
$$




$$
\begin{aligned}
\mathcal{E}\left[\epsilon_{i j}^{f}\right] & =0 \\
\mathcal{E}\left[\left(\epsilon_{i j}^{f}\right)^{2}\right] & =\left(\sigma_{j}^{2}+\sigma_{\nu}^{2}\right) \\
\mathcal{E}\left[\epsilon_{i j}^{f} \epsilon_{i j^{\prime}}^{f}\right] & =0 \\
\mathcal{E}\left[\epsilon_{i j}^{f} \epsilon_{i^{\prime} j}^{f}\right] & =\sigma_{\nu}^{2} \\
\mathcal{E}\left[\epsilon_{i j}^{p} \epsilon_{i j^{\prime}}^{f}\right] & =0 \\
\mathcal{E}\left[\epsilon_{i j}^{p} \epsilon_{i^{\prime} j}^{f}\right] & =(\gamma+1) \sigma_{\nu}^{2} .
\end{aligned}
$$

The results from estimating this model are given in Table 7 . The likelihood function increases substantially to a value of $108.60 .^{15}$

The cost function parameter $\gamma$ is estimated to be 0.67 suggesting that the cost function is fairly close to quadratic $\hat{\eta}=2.49$. This estimate accords closely with the lower bound estimated in Paarsch and Shearer (1999). The estimates of the individual-specific effects reflect the importance of individual heterogeneity that was evident in Table 3. The variance parameters suggest that perception errors are of the same degree of importance in determining productivity as the variance of planting conditions. Note, however, that the estimate of $\gamma \sigma_{j}^{2}$, the determinant of the asymmetry in worker reactions to changing conditions, is very close to zero (its maximum value over the three plots is 0.008 ). This suggests that worker incentives are relatively constant across conditions.

In the presence of perception errors it is important to distinguish between conditional and unconditional productivity. The firm makes a different error on each plot, viewed as an independent draw of $\nu$ from its distribution. Conditional productivity on a given plot is now affected by the size (and sign) of this perception error. That

15 A further generalization of the model allows for correlation between observations on the same day. This would allow for weather effects, for example. Estimates of such a model did not alter the economic conclusions in a significant manner. 
is,

$$
\begin{aligned}
\mathcal{E}\left[Y^{p r} \mid r, \nu\right] & =\frac{1}{r_{j}} \bar{u}(\gamma+1)\left(\frac{\kappa_{h}}{\kappa_{i}}\right)^{\gamma} \exp \left\{(\gamma+1) \nu-.5(\gamma+1)^{2} \sigma_{\nu}^{2}\right\} \\
\mathcal{E}\left[Y^{f w} \mid r, \nu\right] & =\frac{1}{r_{j}} \bar{u} \frac{1}{\gamma+1}(\gamma+1) \gamma^{\frac{-\gamma}{\gamma+1}}\left(\frac{\kappa_{h}}{\kappa_{i}}\right)^{\frac{\gamma}{\gamma+1}} \exp \left\{\frac{\gamma}{\gamma+1} \mathcal{R}_{i}-.5 \gamma\left(\sigma_{j}^{2}+\sigma_{\nu}^{2}\right)\right\} \\
& \exp \left\{\nu-.5 \sigma_{\nu}^{2}\right\} .
\end{aligned}
$$

This breaks the monotonic relationship between piece rates and productivity derived in Lemma 1 and allows for more flexibility in the model.

The random-effects model estimates the unconditional, or marginal distribution of productivity on a given plot

$$
\mathcal{E}\left[Y^{p r} \mid r_{j}\right]=\int_{\nu} \mathcal{E}\left[Y^{p r} \mid r_{j}, \nu\right] f\left(\nu \mid r_{j}\right) d \nu
$$

Substituting from (7.7) and using independence of $\nu$ and $r$ gives

$$
\mathcal{E}\left[Y^{p r} \mid r_{j}\right]=\bar{u}(\gamma+1)\left(\frac{\kappa_{h}}{\kappa_{i}}\right)^{\gamma} \frac{1}{r_{j}} .
$$

Similarly,

$$
\mathcal{E}\left[Y^{f w} \mid r_{j}\right]=\frac{\bar{u}^{\frac{1}{(\gamma+1)}}(\gamma+1)}{r_{j}} \gamma^{\frac{-\gamma}{(\gamma+1)}}\left(\frac{\kappa_{h}}{\kappa_{i}}\right)^{\frac{\gamma}{(\gamma+1)}} \exp \left\{\frac{\gamma}{\gamma+1} \mathcal{R}_{i}-.5 \gamma\left(\sigma_{j}^{2}+\sigma_{\nu}^{2}\right)\right\}
$$

Thus the monotonic relationship between the piece rate and expected productivity derived in Lemma 1 only holds on average over all possible values of $\nu$.

Comparing estimates of the incentive effect to the unrestricted model requires recovering $\mathcal{E}\left[Y^{p r} \mid r_{j}, \nu\right]$ which requires an estimate of $\nu_{j} .{ }^{16}$ To this end, (see Judge et al. 1984) I use

$$
\hat{\nu}_{j}=\frac{\hat{\sigma}_{\nu}^{2}}{n_{j} \hat{\sigma}_{\nu}^{2}+\hat{\sigma}_{j}^{2}} \sum_{i=1}^{n_{j}} \hat{u}_{i j}
$$

16 Note, an alternative would be to estimate the $\nu_{j}$ directly through a fixed-effect model. The two models are inherently related. However the inconvenience of the fixed-effect model is the absence of a direct estimate of $\sigma_{\nu}^{2}$. While it would be possible to recover $\sigma_{\nu}^{2}$ from the squared deviations of the $\nu_{j}$, with only 3 plots this approach was deemed less satisfactory. 
where $\hat{u}_{j}$ is the $i^{t h}$ residual on plot $j$.

The average conditional incentive effect over the three blocks is calculated as 0.213 , with a standard error of 0.015 . This closely matches the unrestricted effect of .198. The conditional incentive effects on each block are estimated to be 0.213 (0.017), on plot $1,0.311$ (0.037), on plot 2, and $0.114(0.046)$ on plot 3. The standard errors, in parentheses, were bootstrapped from the residuals of the parametric model. ${ }^{17}$ Again these values closely match the unrestricted estimates of 0.20 on plot $1,0.31$ on plot 2 , and 0.08 on plot 3 . The average unconditional incentive effect is estimated to be 0.223 with a standard error of 0.016 . The unconditional incentive effects (averaged over all possible values of $\nu$ ) vary much less across plots. These are calculated as 0.194(0.020), on plot 1, 0.228(0.017), on plot 2, and 0.232(0.018), on plot 3. The contrast between the conditional and unconditional incentive effects across plots suggests that the most important variation in incentives is due to the perception errors on the part of the firm rather than varying planting conditions. Note, however, that this does not imply that behaviour is unimportant. The perception errors are not atheoretic error terms that are added to the model ex-post. Rather, they have behavioural implications affecting worker effort and productivity as is evident from (7.7).

The improvement in fit of the model accorded by the introduction of perception errors is also evident from Figure 3 which plots the predicted conditional productivities per plot from the perception-error model along with the unrestricted average productivities. For each plot, the predicted productivity is much closer to its unrestricted counterpart than is the case in Figure 2, presenting convincing evidence that the perception-error model dominates the full information model.

\subsection{Assessing the fit of the Structural Model}

Figure 3 gives some indication that the structural model with perception errors is able to replicate the unrestricted incentive effect quite closely. To consider this in

17 The calculations are based on 1000 bootstrapped samples. The bootstrap procedure randomly sampled residuals with replacement within a given block. 
a more formal manner I perform a bootstrap test of the null hypothesis that these statistics have a common point of convergence. Let $H^{s}$ and $H^{u}$ denote, respectively, the structural and the unrestricted incentive effects, averaged over plots. In enacting the test, I generate bootstrap samples from the residuals of the structural model. For each generated sample, I estimated the structural model, the resulting average (conditional) incentive effect for the experiment, as well as the unrestricted average incentive effect for the experiment. Repeating $B$ times, generates the distribution of the test statistic $\hat{H}^{s}-\hat{H}^{u}$ under the null hypothesis. The 95th percentile of this distribution, based on $B=1000$, is 0.038 ; the observed difference in statistics is 0.015 - suggesting that the null hypothesis is not rejected at the $5 \%$ level.

\section{Policy Analysis}

Estimation of the structural model has two principal benefits. First, it allows the generalization of the incentive effect beyond the experimental sample and second, it permits the evaluation of alternative personnel policies. Two possibilities exist for generalization. First, from Theorem 2, experimental data can be supplemented with non experimental data in order to estimate the variance on plots outside of the experiment. Second, from Theorem 3, a lower bound to the incentive effect on any plot can be calculated from the experimental results. In what follows I present results of the latter approach.

\subsection{The Lower-Bound to the Incentive Effect}

The structural estimates in Table 8 can be used to calculate a lower bound to the incentive effect for any plot of land. From Theorem 3 this is accomplished by evaluating the incentive effect at zero variance. In the presence of perception errors, the conditional lower bound varies from plot to plot (depending on the perception error). As a predictive device, it therefore seems reasonable to present the unconditional lower bound, averaged over all possible values of $\nu$. This is calculated as 
21.7\%. ${ }^{18}$ Consistent with the previous results, this suggests that the unconditional incentive effect will not decrease very much outside of the sample.

\subsection{Alternative Personnel Policies}

One important issue involved in the generalization of experimental results concerns whether a short term experiment can identify the results of a permanent change in policy. Within the current context: does the personnel-policy experiment identify the effects of a permanent change to fixed wages. ${ }^{19}$ To see that a permanent change will not necessarily have the same effects as those observed in the experiment, recall that effort levels in the experiment are enforced by the future surplus to the worker of returning to piece rates. If the change in policy is permanent, this surplus must be generated by the fixed wage. This is particularly important when comparing the unit costs of the fixed wages to piece rates. Unit costs are higher under fixed wages than piece rates in the experiment. Yet, if the firm could enforce effort levels at lower wages than those observed in the experiment, then fixed wages may be a viable alternative. In this section I consider the levels of fixed wages that support the effort levels observed in the experiment within a stationary environment, holding labour market conditions and monitoring technology constant.

From Section 4, the efficiency wage needed to enforce a given effort level, $E$, must satisfy the no-shirking condition

$$
\delta \beta[\mathcal{E}[V \mid \text { shirk }]-\mathcal{E}[V \mid F]] \geq C(E)
$$

This states simply that the expected cost of shirking must be greater than or equal to the cost of effort. Rearranging, and assuming that the firm chooses the smallest wage that satisfies the no-shirking condition, gives

$$
\hat{w}=C(E) \frac{(1-\beta)}{\beta \delta}+C(E)+(1-\beta) \mathcal{E}[V \mid F] .
$$

\footnotetext{
18 It is also possible to calculate the lower bound conditional on the individuals observed on a particular plot.These are calculated to be: 0.19 (plot 1), 0.22 (plot 2) and 0.22 (plot 3).

19 This is an example of what Ferrall (2001) calls terminal bias.
} 
Equation (8.1) gives the efficiency wage that the firm would have to pay to enforce different effort levels, $E$. Evaluating (8.1) at the fixed-wage effort level, $e^{f w}$, and using (5.12) and (5.5) gives

$$
\begin{aligned}
\hat{w}_{i}^{f w} & =\delta \beta\left[\mathcal{E}\left[V_{i} \mid P R\right]-\mathcal{E}\left[V_{i} \mid F\right]\right]+\left(\frac{\kappa_{h}}{\kappa_{i}}\right)^{\gamma} \bar{u} \\
& =\exp \left\{\mathcal{R}_{i}\right\}+\exp \left\{a_{0}+\gamma\left(\ln \kappa_{1_{i}}-\ln \kappa_{i}\right)\right\} .
\end{aligned}
$$

Evaluating (8.2) at the estimated parameter values gives an average efficiency wage of $\$ 200.04$ that would give the same level of effort as that provided under fixed wages in the experiment. This suggests that the effort levels observed under fixed wages could have been supported by a wage less than that actually paid (fixed wages averaged $\$ 216.70)$. However, even at this lower wage, the unit costs of planting under fixed (efficiency) wages would have been 0.191 dollars per tree. This represents a $2.69 \%$ increase in cost over piece rate planting which has unit costs of 0.186 .

I next consider the efficiency wage that would enforce effort levels equivalent to those observed under piece rates. Evaluating (8.1)at piece rate effort levels and taking expectations gives

$$
\hat{w}_{i}^{p r}=\frac{(1-\beta)}{\delta \beta} \mathcal{E}\left[C\left(e^{p r}\right)-C\left(e^{f w}\right)\right]+\left(\frac{\kappa_{h}}{\kappa_{i}}\right)^{\gamma} \bar{u}(\gamma+1) .
$$

Since the first part of (8.3) is positive, a lower bound to the efficiency wage can be calculated as

$$
\left(\frac{\kappa_{h}}{\kappa_{i}}\right)^{\gamma} \bar{u}(\gamma+1)
$$

But this is simply the expected wage for individual $i$ when planting under piece rates. Therefore, unit costs must be at least as high under efficiency wages as they are under piece rates. Intuitively, earnings and effort under piece rates provide a surplus that is capable of enforcing the effort level observed under fixed wages in the experiment. In order to enforce the higher level of effort observed under piece rates, a higher wage must be paid. 


\section{Discussion and Conclusion}

This study adds to a growing body of research measuring incentive effects. The use of experimental methods permits the direct identification of the incentive effect through a comparison of average productivity under different compensation systems. The unrestricted analysis of the experimental data confirms the existence of an incentive effect, measured at approximately $20 \%$. Workers do react to the incentives embodied within the compensation system confirming previous non experimental results obtained in Paarsch and Shearer (2000) and Lazear (2000).

This study also demonstrates the potential value of small-scale experiments within firms to evaluate the effects of alternative human resource policies. It presents an alternative experimental methodology to previous computerized experiments on compensation systems. For example, Bull, Schotter and Weigelt (1987) chose the structural parameters of the participants cost of effort function and reward function and then considered whether actual effort choices corresponded with predicted ones. Here, the observed reaction of workers to changes in the compensation system within the experiment is used to identify the structural parameters which are then used to generalize the experimental results to non experimental settings.

The ability to generalize experimental results is ultimately limited by identification which is determined, in turn, by the model and variation in the data. The model developed in this paper permits generalization in two directions: prediction of the incentive effect on non experimental planting conditions; and the cost of a permanent change in policy to fixed wages. Yet, both the simplicity of the model and the experiment, limit generalization in other directions. Perhaps most importantly, the estimated incentive effect is conditional on the personnel policy used in this particular firm as well as the labour market conditions at the time the experiment was conducted. For example, a lack of information and variability in labour market conditions, due to the short duration of the experiment, inhibits consideration of how fixed wages would perform at other times of the year or under different labour-market conditions. As well, given a lack of information over the monitoring 
technology of workers the estimates are unable to identify or predict how monitoring affects incentives.

The results also suggest areas for future research. The strict interpretation of the structural approach suggests that it is mere coincidence that the results presented here accord with Lazear's (2000) study. Lazear studied windshield installers in the United States - a different task, using different technology, and in a different labour market. There is no reason to believe that the structural parameters are the same in the two situations. Replication studies in other industries will allow for further comparisons along these lines. The efficiency wage model developed here presents a limited long run analysis of the effect of a permanent change to fixed wages. Matching models (Stiglitz, 1975, for example) suggest that workers may self-select into firms based on the compensation system, implying a permanent change may lead to turnover within the firm. Lazear (2000) found that that turnover was significant after a change from fixed wages to piece rates. Labour demand may be affected as well since the amount of labour required to produce any given level of output changes. Extending the analysis to allow for general-equilibrium effects in incentive models would provide further insight into the long-run effects of incentives. 
Table 1

Summary Statistics: Daily Productivity, Earnings and Unit Costs

Experimental Sample

\begin{tabular}{lrlccl}
\hline \hline & & Trees: & & Earnings: & Unit Costs: \\
\hline & Observations & Mean & St.Dev. & Mean & Mean \\
\hline Full Sample & 120 & 1146.67 & 278.54 & 223.78 & 0.20 \\
Piece Rate & 60 & 1256 & 325.27 & 230.85 & 0.186 \\
Fixed Wages & 60 & 1037.33 & 162.38 & 216.70 & 0.214 \\
\hline
\end{tabular}

Table 2 Summary Statistics: Average Productivity by Plot Experimental Sample

\begin{tabular}{lrrrrrr}
\hline \hline Plot & Obs & Rate & Mean & St.Dev. & PR & FW \\
\hline 1 & 24 & 0.17 & 1273.33 & 188.14 & 1390.00 & 1156.67 \\
2 & 48 & 0.18 & 1321.25 & 247.90 & 1500.83 & 1141.67 \\
3 & 48 & 0.20 & 908.75 & 143.27 & 944.17 & 873.33 \\
\hline
\end{tabular}

Table 3

Summary Statistics: Average Productivity by Planter and Pay System Experimental Sample

\begin{tabular}{llllll}
\hline \hline Planter & \multicolumn{1}{l}{ Observations } & Total & PR & FW & Difference \\
\hline 1 & 16 & 1127.50 & 1275.00 & 980.00 & 295.00 \\
2 & 12 & 1098.33 & 1220.00 & 976.67 & 243.33 \\
3 & 12 & 1226.67 & 1430.00 & 1023.33 & 406.67 \\
4 & 16 & 992.50 & 1000.00 & 985.00 & 15.00 \\
5 & 12 & 1163.33 & 1266.67 & 1060.00 & 206.67 \\
6 & 4 & 1330.00 & 1470.00 & 1190.00 & 280.00 \\
7 & 16 & 1121.25 & 1165.00 & 1077.50 & 87.50 \\
8 & 16 & 1157.50 & 1255.00 & 1060.00 & 195.00 \\
9 & 16 & 1252.50 & 1420.00 & 1085.00 & 335.00 \\
\hline
\end{tabular}


Table 4 Bootstrapped Unrestricted Incentive Effects: by Plot

\begin{tabular}{llll}
\hline \hline Plot: & 1 & 2 & 3 \\
\hline$H^{1}:$ & 0.202 & 0.312 & 0.082 \\
Standard Error & 0.016 & 0.027 & 0.038 \\
Estimated Bias & $7.3 \mathrm{e}-4$ & 0.001 & 0.003 \\
Relative Bias & 0.045 & 0.050 & 0.086 \\
$H^{2}:$ & 0.202 & 0.315 & 0.081 \\
Standard Error & 0.015 & 0.027 & 0.037 \\
Estimated Bias & $4.3 \mathrm{e}-4$ & $3.8 \mathrm{e}-4$ & $3.3 \mathrm{e}-4$ \\
Relative Bias & 0.028 & 0.014 & 0.009 \\
\hline
\end{tabular}

Table 5

Summary Statistics: Daily Fixed-Wage Productivity by Planter and Plot Experimental Sample

\begin{tabular}{lllllll}
\hline \hline Planter & $\begin{array}{l}\text { Plot 1 } \\
\text { Average }\end{array}$ & Std Dev & $\begin{array}{l}\text { Plot 2 } \\
\text { Average }\end{array}$ & Std Dev & $\begin{array}{l}\text { Plot 3 } \\
\text { Average }\end{array}$ & Std Dev \\
\hline 1 & 990.00 & 42.43 & 1126.67 & 61.10 & 826.67 & 94.52 \\
2 & & & 1120 & 52.92 & 833.33 & 102.63 \\
3 & & & 1153.33 & 120.55 & 893.33 & 130.13 \\
4 & 1060.00 & 84.85 & 1073.33 & 57.74 & 846.67 & 120.55 \\
5 & & & 1226.67 & 64.29 & 893.33 & 113.72 \\
6 & 1190.00 & 70.71 & & & & \\
7 & 1270.00 & 14.14 & 1153.33 & 128.58 & 873.33 & 94.52 \\
8 & 1230.00 & 14.14 & 1126.67 & 61.10 & 880.00 & 72.11 \\
9 & 1200.00 & 0.00 & 1153.33 & 30.55 & 940.00 & 105.83 \\
\hline
\end{tabular}


Table 6

Parameter Estimates of Restricted Model:

Experimental Sample

Sample Size $=120$

\begin{tabular}{lrrr}
\hline \hline Parameter & (Coef.) & (Std. Error) & (P-Value) \\
\hline$\alpha_{0}$ & 4.920 & 0.139 & 0.000 \\
$\gamma$ & 0.652 & 0.229 & 0.003 \\
$\kappa_{1}-\kappa_{2}$ & 0.170 & 0.124 & 0.174 \\
$\kappa_{1}-\kappa_{3}$ & 0.420 & 0.216 & 0.054 \\
$\kappa_{1}-\kappa_{4}$ & -0.281 & 0.133 & 0.036 \\
$\kappa_{1}-\kappa_{5}$ & 0.323 & 0.170 & 0.060 \\
$\kappa_{1}-\kappa_{6}$ & 0.153 & 0.158 & 0.334 \\
$\kappa_{1}-\kappa_{7}$ & 0.083 & 0.155 & 0.595 \\
$\kappa_{1}-\kappa_{8}$ & 0.181 & 0.217 & 0.404 \\
$\kappa_{1}-\kappa_{9}$ & 0.303 & 0.132 & 0.024 \\
$\sigma_{1}$ & 0.078 & 0.011 & 0.000 \\
$\sigma_{2}$ & 0.031 & 0.006 & 0.000 \\
$\sigma_{3}$ & 0.195 & 0.031 & 0.000 \\
$\mathcal{R}_{1}$ & 3.834 & 0.355 & 0.000 \\
$\mathcal{R}_{2}$ & 3.982 & 0.388 & 0.000 \\
$\mathcal{R}_{3}$ & 3.812 & 0.456 & 0.000 \\
$\mathcal{R}_{4}$ & 4.227 & 0.241 & 0.000 \\
$\mathcal{R}_{5}$ & 4.051 & 0.388 & 0.000 \\
$\mathcal{R}_{6}$ & 4.054 & 0.359 & 0.000 \\
$\mathcal{R}_{7}$ & 4.259 & 0.293 & 0.000 \\
$\mathcal{R}_{8}$ & 4.088 & 0.384 & 0.000 \\
$\mathcal{R}_{9}$ & 3.934 & 0.452 & 0.000 \\
Logarithm of the Likelihood Function: & 87.451 & & \\
\hline
\end{tabular}


Table 7

Parameter Estimates of Restricted Model with Perception Errors (Random Effects): Experimental Sample

Sample Size $=120$

\begin{tabular}{|c|c|c|c|}
\hline Parameter & (Coef.) & (Std. Error) & $\overline{(P-V a l u e)}$ \\
\hline$\alpha_{0}$ & 4.898 & 0.138 & 0.000 \\
\hline$\gamma$ & 0.670 & 0.223 & 0.001 \\
\hline$\kappa_{1}-\kappa_{2}$ & 0.057 & 0.103 & 0.579 \\
\hline$\kappa_{1}-\kappa_{3}$ & 0.301 & 0.171 & 0.078 \\
\hline$\kappa_{1}-\kappa_{4}$ & -0.311 & 0.156 & 0.047 \\
\hline$\kappa_{1}-\kappa_{5}$ & 0.163 & 0.125 & 0.195 \\
\hline$\kappa_{1}-\kappa_{6}$ & 0.120 & 0.103 & 0.245 \\
\hline$\kappa_{1}-\kappa_{7}$ & -0.003 & 0.069 & 0.966 \\
\hline$\kappa_{1}-\kappa_{8}$ & 0.010 & 0.087 & 0.253 \\
\hline$\kappa_{1}-\kappa_{9}$ & 0.248 & 0.142 & 0.080 \\
\hline$\sigma_{1}$ & 0.064 & 0.007 & 0.000 \\
\hline$\sigma_{2}$ & 0.039 & 0.007 & 0.000 \\
\hline$\sigma_{3}$ & 0.111 & 0.014 & 0.000 \\
\hline $\mathcal{R}_{1}$ & 3.877 & 0.430 & 0.000 \\
\hline $\mathcal{R}_{2}$ & 4.000 & 0.403 & 0.000 \\
\hline $\mathcal{R}_{3}$ & 3.848 & 0.488 & 0.000 \\
\hline $\mathcal{R}_{4}$ & 4.252 & 0.272 & 0.000 \\
\hline $\mathcal{R}_{5}$ & 4.108 & 0.380 & 0.000 \\
\hline $\mathcal{R}_{6}$ & 4.080 & 0.412 & 0.000 \\
\hline $\mathcal{R}_{7}$ & 4.271 & 0.319 & 0.000 \\
\hline $\mathcal{R}_{8}$ & 4.108 & 0.380 & 0.000 \\
\hline $\mathcal{R}_{9}$ & 3.960 & 0.448 & 0.000 \\
\hline$\sigma_{\nu}$ & 0.076 & 0.010 & 0.000 \\
\hline Logarithm of the Likelihood Function: & 108.603 & & \\
\hline
\end{tabular}




\section{Proof of Theorem 1.}

$\gamma$ is identified by the ratio of variances between fixed-wage and piece-rate productivity on the same plot. Once these restrictions are imposed in (6.1) the plot-specific terms identify $\sigma_{j}^{2}$, the individual-specific terms in the piece rate equation then identify $\left(\ln \kappa_{i_{1}}-\ln \kappa_{i}\right)$ and the constant term identifies $\ln \bar{u}+\gamma\left(\ln \kappa_{h}-\ln \kappa_{i_{1}}\right)$. The rent terms, $\mathcal{R}_{i}$ are then identified by the individual-specific terms in the fixed-wage equation. Finally, the difference in means, $\mu_{j_{1}}-\mu_{j}$, is identified from (5.4)by

$$
\ln r_{j_{1}}-\ln r_{j}+(\gamma+1)\left(\sigma_{j}^{2}-\sigma_{j_{1}}^{2}\right)
$$

\section{Proof of Lemma 1.}

The proof of Lemma 1 follows directly from substituting (5.4) into the expectation of (5.6).

\section{Proof of Lemma 2.}

The proof of Lemma 2 follows directly from substituting (5.4) into the expectation of (5.14).

\section{Proof of Theorem 2.}

The proof follows directly from Lemma 1 and Lemma 2.

\section{Proof of Theorem 3.}

The proof follows directly from the fact that (6.4) is increasing in $\sigma^{2}$. 


\section{References}

Burtless, G., 1995. "The Case for Randomized Field Trails in Economic and Policy Research." Journal of Economic Perspectives, 9(2): 63-84.

Bull, C. 1987. "The Existence of Self-Enforcing Implicit Contracts." Quarterly Journal of Economics, 102, 147-59.

Bull, C., A. Schotter and K. Weigelt, 1987. "Tournaments and Piece Rates: An Experimental Study." Journal of Political Economy, 95(1): 1-33.

Chiappori, P.A. and B. Salanié, 2000. "Testing Contract Theory: A Survey of Some Recent Work." Mimeo, Department of Economics University of Chicago.

Copeland, A. and C. Monet, 2002. "The Welfare Effects of Incentive Schemes," Mimeo, University of Minnesota.

Ehrenberg, R. 1990. Do Compensation Policies Matter?. Industrial \& Labor Relations Review, 43(3).

Efron, B., and R. J. Tibshirani 1993. An Introduction to the Bootstrap, New York, Capman and Hall.

Fehr, E. and Simon Gachter 2000. "Fairness and Retaliation: The Economics of Reciprocity." Journal of Economic Perspectives, 14: 159-181.

Ferrall, C., 2002 "Estimation and Inference in Social Experiments" Mimeo, Queen's University.

Ferrall, C. and B. Shearer, 1999. "Incentives and Transaction Costs within the Firm: Estimating an Agency Model Using Payroll Records." Review of Economic Studies, 66(2): 309-338.

Flinn, C. 1997. "Equilibrium Wage and Dismissal Processes, Journal of Business and Economic Statistics, 15: 221-236.

Haley, M. forthcoming. "The Response of Worker Effort to Piece Rates: Evidence from the Midwest Logging Industry." Journal of Human Resources.

Hart, O. and B. Holmstrom. 1987. "The Theory of Contracts." In Advances in Economic Theory Fifth World Congress, ed. by T. Bewley. Cambridge, United Kingdom: Cambridge University Press.

Heckman, J. and J. Smith, 1995. "Assessing the Case for Social Experiments." Journal of Economic Perspectives, 9(2): 85-110. 
Ichniowski, C., K. Shaw and G. Prennushi, 1997. "The Effects of Human Resource Management Practices on Productivity: A Study of Steel Finishing Lines." American Economic Review, 87(3): 291-313.

Judge, G., W. E. Griffiths, R. C. Hill, H. Lutkepohl, T-C. Lee, 1985. The Theory and Practice of Econometrics. John Wiley and Sons, New York.

Keane, M. and K. Wolpin, 1997. "Introduction to the JBES Special Issue on Structural Estimation in Applied Microeconomics." Journal of Business and Economic Statistics, 15(2): 111-114.

Lazear, E. 1998. Personnel Economics for Managers. New York: John Wiley \& Sons.

Lazear, E. 2000. "Performance Pay and Productivity," American Economic Review, 90(5): 1346-1361.

Margiotta, M. and R. Miller 2001. "Managerial Compensation and the Cost of Moral Hazard." International Economic Review, 84(3): 669-720.

MacKinnon, J. B. and A. Smith 2000. "Approximate Bias Correction in Econometrics." Journal of Econometrics, 85(2): 205-30.

MacLeod, W. and J. Malcomson. 1989. "Implicit Contracts, Incentive Compatibility, and Involuntary Unemployment." Econometrica, 57(2): 447-480.

Milgrom, P. and J. Roberts. 1992. Economics, Organization and Management. Englewood Cliffs, New Jersey: Prentice Hall.

Paarsch, H. and B. Shearer. 1999. "The Response of Worker Effort to Piece Rates: Evidence fro the British Columbia Tree-Planting Industry." Journal of Human Resources Fall, 34(4): 643-667.

Paarsch, H. and B. Shearer. 2000. "Piece Rates, Fixed Wages, and Incentive Effects: Statistical Evidence from Payroll Records." International Economic Review February, 41(1): 59-92.

Prendergast, C. 1999. "The Provision of Incentives in Firms." Journal of Economic Literature, XXXVII, March: 7-63.

Shapiro, C. and J. Stiglitz. 1984. "Equilibrium Unemployment as a Worker Discipline Device." American Economic Review, 74(3): 433-444.

Shearer, B. 1996. "Piece Rates, Principal-Agent Models, and Productivity Profiles: Parametric and Semi-Parametric Evidence from Payroll Records." Journal of Human Resources, 31(2): 275-303. 
Stiglitz, J. 1975. "Incentives, Risk, and Information: Notes Towards a Theory of Hierarchy." Bell Journal of Economics 6(2): 552-79. 
Figure 1: Expected Productivity Isoquants

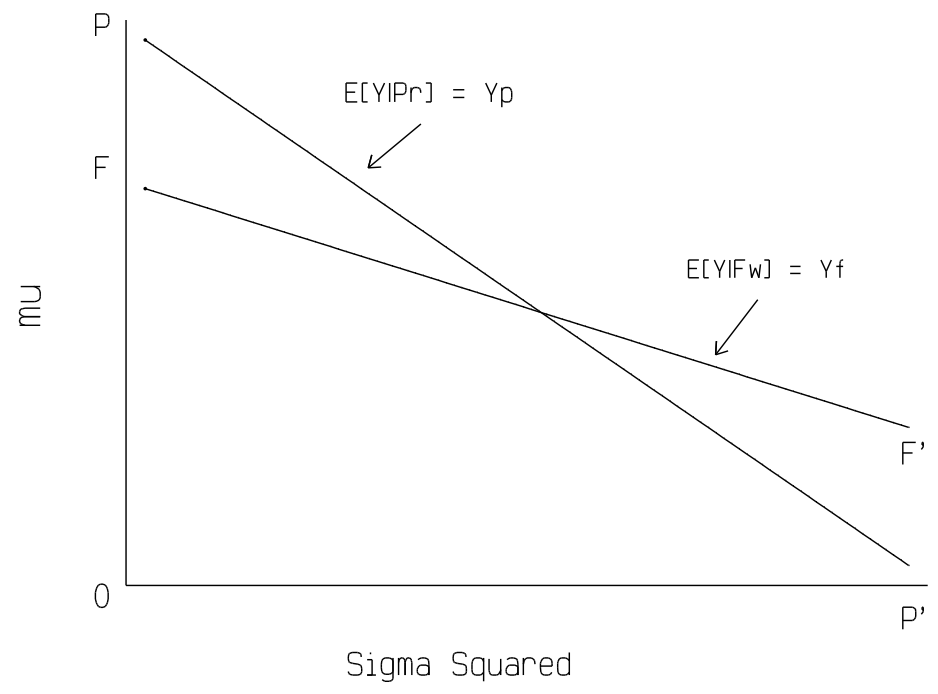


Figure 2: Predicted and Observed Average Productivity by Plot

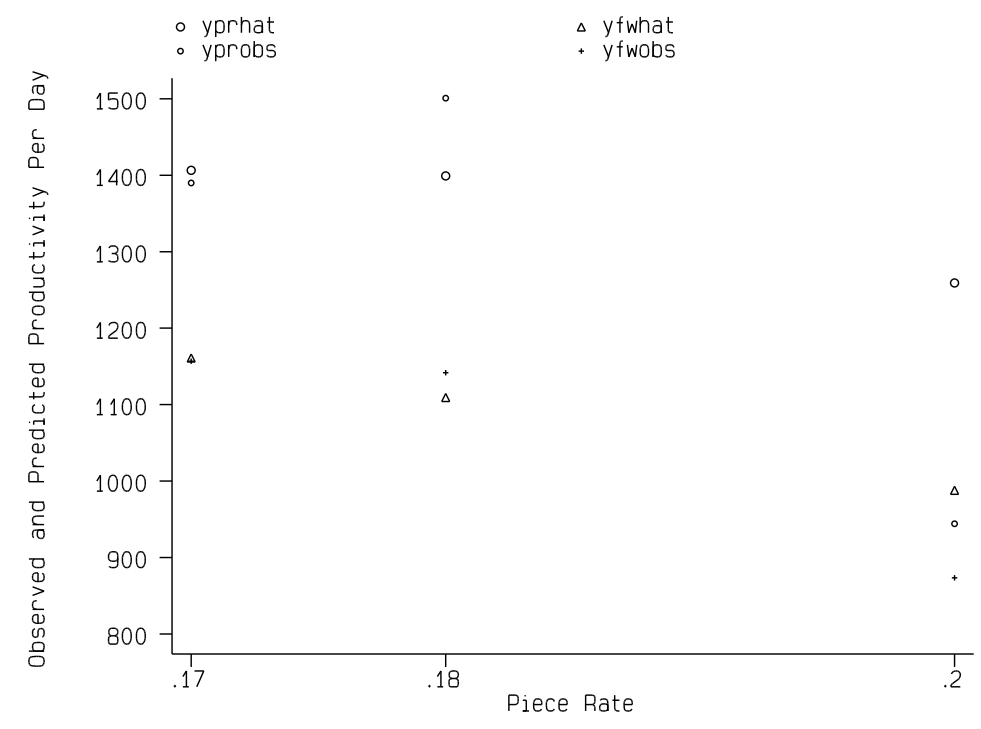

Figure 3: Predicted and Observed Average Productivity by Plot With Perception Errors

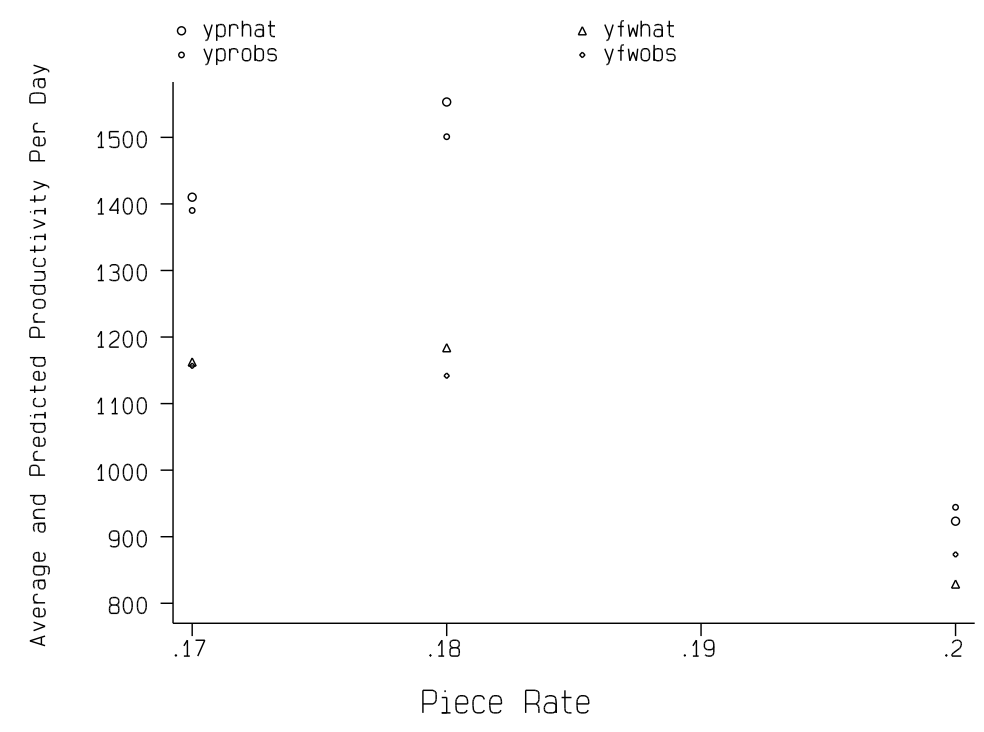

39 